\title{
Treatment-Refractory Sternocostoclavicular Hyperostosis
}

\author{
Ralph Yachoui, MD; Mazen Kreidy, MD and Brian J. Parker, MD
}

\begin{abstract}
Sternocostoclavicular hyperostosis $(\mathrm{SCCH})$ is an infrequent chronic inflammatory disorder of the axial skeleton of unknown origin. SCCH goes often unrecognized due to a low level of awareness for the disorder. It typically presents with relapsing and remitting pain in the shoulder, neck, and anterior chest wall area with occasional swelling and tenderness of the sternoclavicular area. The diagnosis is confirmed radiologically by sclerosis and hyperostosis of the sternoclavicular joints. There have been several reports in which intravenous bisphosphonates and tumor necrosis factor-inhibitors have shown reasonable efficacy in the treatment of this disorder. We report a patient with a long history of $\mathrm{SCCH}$ in whom pamidronate $60 \mathrm{mg}$ intravenously every 3 months for 3 years failed to reduce symptom severity and improve radiologic findings.
\end{abstract}

Keywords: Bisphosphonates; Pamidronate; Sternocostoclavicular hyperostosis;

Tumor necrosis factor-inhibitors

$\mathrm{S}$ ternocostoclavicular hyperostosis $(\mathrm{SCCH})$ is a rare chronic inflammatory condition of the axial skeleton that was first described in $1968 .{ }^{1}$ SCCH typically presents with intermittent attacks of severe pain, redness, and swelling in the sternoclavicular region often associated with considerable impairment of shoulder girdle movement. ${ }^{2}$ The exact incidence of $\mathrm{SCCH}$ is unknown, as many cases go undiagnosed. ${ }^{3}$ Over the last two decades, there have been several reports in which intravenous bisphosphonates and tumor necrosis factor (TNF)-inhibitors have shown reasonable efficacy in the treatment of this disorder ${ }^{4-9}$ Here, we report the clinical, laboratory, and radiologic data of a patient with treatment-refractory SCCH.

\section{Case Report}

A Caucasian woman, aged 28 years, was seen in our clinic because of a long history of upper shoulder girdle and anterior chest wall pain dating to age 18 . The patient recalls developing intermittent episodes of painful swelling of the sternum, clavicles, and upper ribs that became more persistent with each episode. The pain and swelling did not decrease with physical therapy or multiple analgesics including corticosteroids and ibuprofen.

She carried a medical diagnosis of type I diabetes mellitus, depression and affective disorders, ulcerative colitis with backwash ileitis, dyslipidemia, hypertension, seizures, and right hemicolectomy for moderately differentiated adenocarcinoma of the ascending colon which was diagnosed at age 28. Medications included alprazolam, duloxetine, mesalamine, insulin, losartan, pravastatin, lamotrigine, and ibuprofen. She had no known allergies. She had a 20 pack per year smoking history until 5 years ago, and she drinks alcohol occasionally. There was no family history of rheumatic diseases. On examination, she was exquisitely tender along the clavicle bilaterally and at the manubriosternal joint and proximal sternum. The appendicular skeleton was without synovitis or effusion. No skin lesions were found.

Achest radiograph showed sclerosis and exuberant enlargement of involved bone (figure 1A). A computed tomography (CT) scan revealed extensive mature ossification of the sternoclavicular joints and first costochondral junctions, extending into the soft tissues, consistent with $\mathrm{SCCH}$ (figures $1 \mathrm{~B}$ and 2A). Axial imaging demonstrated additional findings of diffuse idiopathic skeletal hyperostosis throughout the thoracic and lumbar spine. No sacroiliitis was seen on magnetic resonance imaging (MRI).

The patient had a microcytic anemia with a hemoglobin level of $11.3 \mathrm{~g} / \mathrm{dL}$. Erythrocyte sedimentation rate was $31 \mathrm{~mm} / \mathrm{hr}$, and C-reactive protein was $3.6 \mathrm{mg} / \mathrm{dL}$. Tests of renal, liver,
Corresponding Author: Ralph Yachoui, MD, Division of Rheumatology, Department of Medicine, David Geffen School of Medicine, University of California-Los Angeles, 10833 LeConte Avenue, Los Angeles, California 90095, Phone: (3I0) 825-6373, Email: ryachoui@mednet.ucla.edu
Received: December 5, 2016

Revised: April 13, 2017

Accepted: June I, 2017

doi: $10.3121 / \mathrm{cmr} .2017 .1352$ 

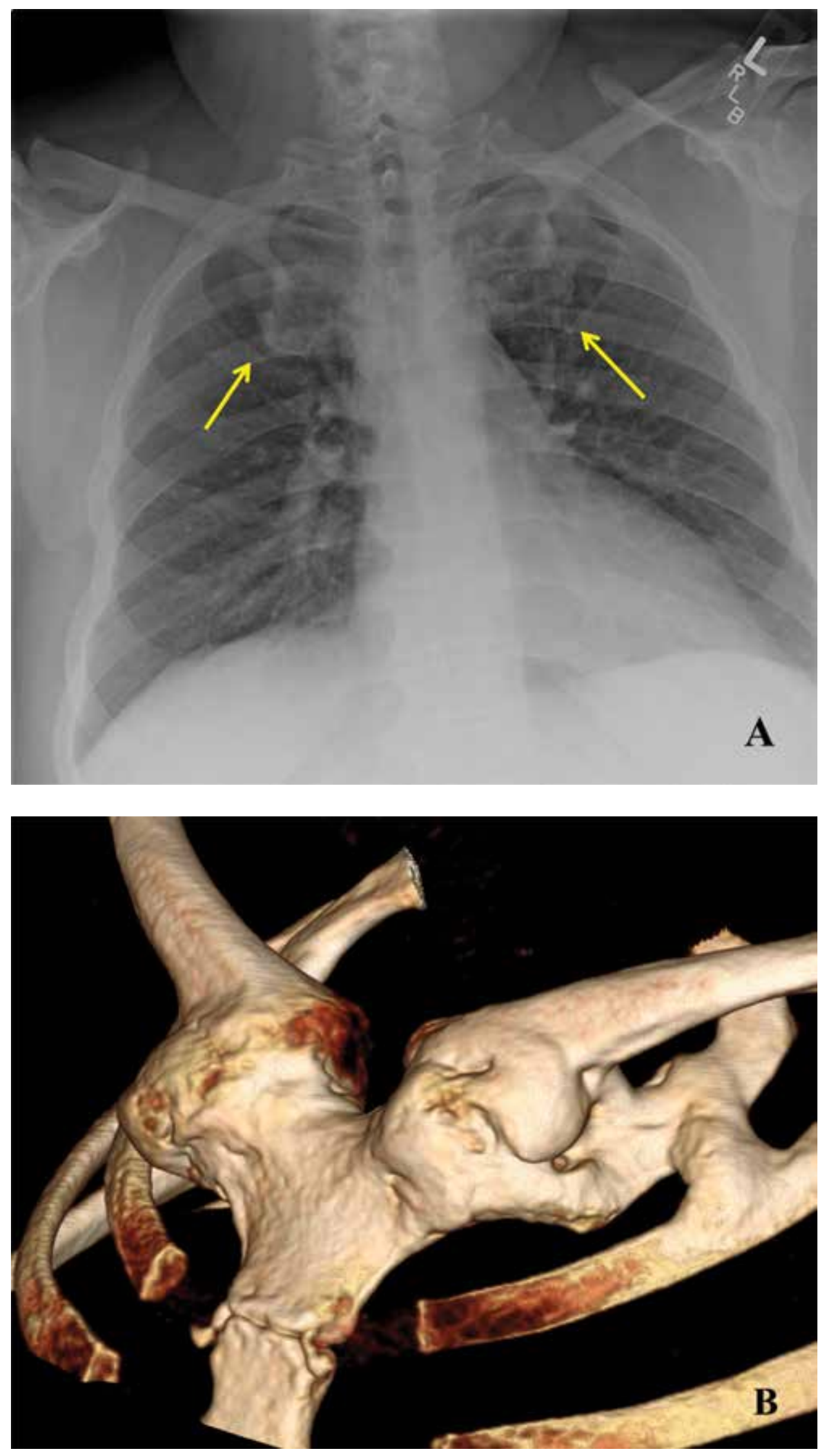

Figure 1. Chest radiograph (A) and computed tomography (CT) scan with $3 D$ reformatted image (B) show marked hyperostosis of bilateral sternocostoclavicular joints (arrows). The ossification extends into the soft tissue with a large bony bridge between the left $1^{\text {st }}$ and $2^{\text {nd }}$ ribs. 

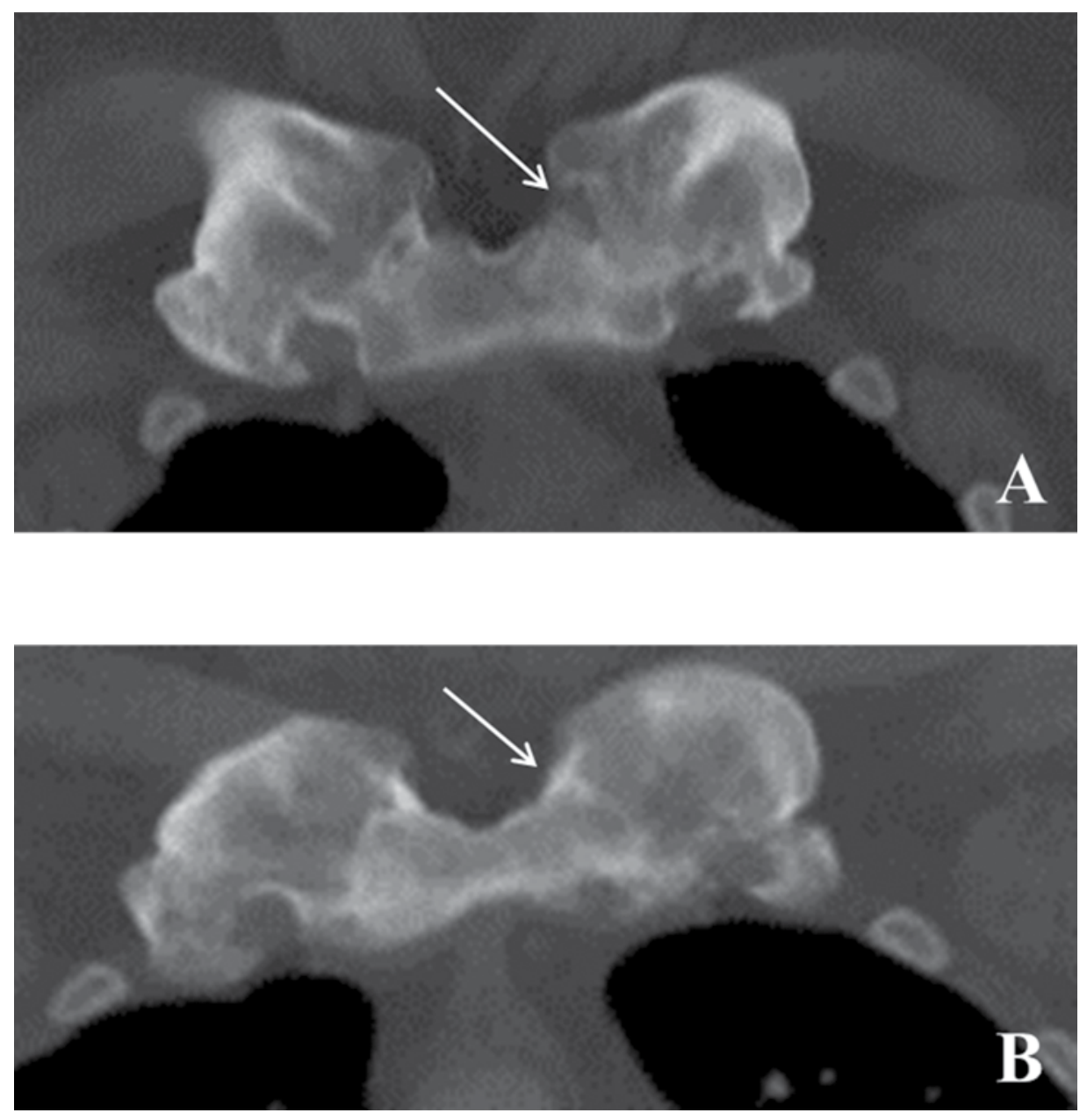

Figure 2. Computed tomography (CT) scan of the chest with coronal reformatted images reveals slight progressive mature ossification of the bilateral sternoclavicular joints (arrows) pre- (A) and post- (B) treatment.

thyroid, and parathyroid function were normal, as were blood levels for vitamin D, calcium, phosphorus, retinol, fluoride, creatine kinase, and hepatitis $\mathrm{C}$. Bone turnover markers consisting of serum total alkaline phosphatase and urinary collagen type 1 cross-linked N-telopeptide were normal. Rheumatoid factor and HLA B27 were negative. A dualenergy X-ray absorptiometry scan was normal.

Initial brief (6-month) treatment with infliximab, a TNFinhibitor agent, was unsuccessful in improving clinical symptoms. Intravenous pamidronate was then administered at a dose of $60 \mathrm{mg}$ given as a 2- to 3-hour infusion every 3 months. There were no relevant adverse events associated with pamidronate treatment. After a possible initial improvement in pain and stiffness following each injection, no clinical benefit ensued by the end of her series of 13 pamidronate injections. Her anemia and raised inflammatory markers persisted after treatment. A repeat chest CT scan obtained at the end of therapy failed to demonstrate radiologic improvement in mature ossification of the bilateral sternoclavicular joints (figure 2B).

\section{Discussion}

$\mathrm{SCCH}$ is a distinct clinical entity that causes progressive hyperostosis of the sternocostoclavicular joints and eventual soft tissue ossification. ${ }^{1,2}$ Some authors believe $\mathrm{SCCH}$ belongs to the spectrum of SAPHO syndrome (synovitis, acne, pustulosis, hyperostosis, and osteitis). $\mathrm{SCCH}$ is largely underdiagnosed due to a low level of awareness for the disorder, and therefore it may be more common than currently believed. ${ }^{3} \mathrm{SCCH}$ is a disorder of midlife, with a slight female predilection. ${ }^{10}$ The condition is bilateral in most patients. The spine, sacroiliac joints, and peripheral joints may also be affected. ${ }^{3}$ No specific diagnostic test for $\mathrm{SCCH}$ is available; the clinical diagnosis is based on pattern recognition and exclusion. It is important to differentiate this entity from the seronegative spondyloarthropathies, infectious osteomyelitis, bone metastasis, and condensing osteitis of the clavicle. ${ }^{11} \mathrm{We}$ found a unique association with diffuse idiopathic skeletal hyperostosis in our case.

The exact pathophysiology of SCCH remains unclear. A nonspecific chronic sterile inflammation is typically seen on histology. The inflammatory osteitis and localized increased 
bone turnover result in thickening of trabecular bone and formation of osteoid tissue, eventually giving the characteristic hyperostotic bone changes in the sternoclavicular area. ${ }^{12}$ The common clinical picture is one of relapsing and remitting pain in the shoulder, neck, and anterior chest wall area with occasional swelling and tenderness of the sternoclavicular area. ${ }^{3}$ Computed tomography (CT) has the ability to detect sclerotic bone trabeculae not obvious on plain radiographs. ${ }^{13}$ Whole-body bone scintigraphy typically demonstrates increased radiotracer activity in the sternal manubrium and in the adjacent clavicles and ribs; a distinctive finding known as the "bullhead" sign. ${ }^{13}$ Results of clinical history, laboratory, and radiologic studies all support the diagnosis of $\mathrm{SCCH}$ in the present case.

Treatment first involves non-steroidal anti-inflammatory drugs and glucocorticoids, which are sometimes effective in alleviating pain and local inflammation, but do not prevent radiographic progression and the risk of secondary degenerative changes. ${ }^{11}$ In advanced stages of the disease, surgical resection of the ossifications may be needed. ${ }^{11}$ Preliminary experience supports the use of TNF-inhibitors and intravenous bisphosphonates in $\mathrm{SCCH}^{4-9}$ Ringe and colleagues 5 administered $2 \mathrm{mg}$ of intravenous ibandronate every 3 months for up to a year to three patients with longstanding refractory SCCH and evaluated clinical, laboratory, and imaging at baseline and at 1 year. There was a prompt persistent pain relief, a gradual decline in inflammatory markers, and improvement in radiographic and scintigraphic findings. We used pamidronate $60 \mathrm{mg}$ intravenously every 3 months for 3 years. Although the treatment was well tolerated, lasting reduction in symptom severity and radiologic improvement were not observed. Further clinical studies are therefore needed to determine the future role of bisphosphonates in $\mathrm{SCCH}$.

\section{References}

1. Kato T, Kambara A, Hoshi E. A case with osteomyelitis of both clavicles associated with pustulosis palmaris and plantaris. Seiki Geka 1968;19:590-593.

2. Köhler H, Uehlinger E, Kutzner J, Weihrauch TR, Wilbert L, Schuster R. Sternocosto-clavicular hyperostosis: A hitherto undescribed entity. Dtsch Med Wochenschr 1975;100:15191523.

3. Kalke S, Perera SD, Patel ND, Gordon TE, Dasgupta B. The sternoclavicular syndrome: experience from a district general hospital and results of a national postal survey. Rheumatology (Oxford) 2001;40:170-177.

4. Kopterides P, Pikazis D, Koufos C. Successful treatment of SAPHO syndrome with zoledronic acid. Arthritis Rheum 2004;50:2970-2973.

5. Ringe JD, Faber H, Farahmand P. Rapid pain relief and remission of sternocostoclavicular hyperostosis after intravenous ibandronate therapy. J Bone Miner Metab 2006;24:87-93.

6. Colina M, La Corte R, Trotta F. Sustained remission of SAPHO syndrome with pamidronate: a follow-up of fourteen cases and review of the literature. Clin Exp Rheumatol 2009;27:112-115.
7. Olivieri I, Padula A, Ciancio G, Salvarani C, Niccoli L, Cantini F. Successful treatment of SAPHO syndrome with infliximab: report of two cases. Ann Rheum Dis 2002;61:375-376.

8. Wagner AD, Andresen J, Jendro MC, Hulsemann JL, Zeidler H. Sustained response to tumor necrosis factor alpha-blocking agents in two patients with SAPHO syndrome. Arthritis Rheum 2002;46:1965-1968.

9. Marshall H, Bromilow J, Thomas AL, Arden NK. Pamidronate: a novel treatment for the SAPHO syndrome? Rheumatology (Oxford) 2002;42:231-233.

10. Van der Kloot WA, Chotkan SA, Kaptein AA, Hamdy NA. Diagnostic delay in sternocostoclavicular hyperostosis: Impact on various aspects of quality of life. Arthritis Care Res (Hoboken) 2010;62: 251-257.

11. Caroll MB. Sternocostoclavicular hyperostosis: a review. Ther Adv Musculoskelt Dis 2011;3:101-110.

12. Kohler H, Uehlinger E, Kutzner J, et al. Sternocostoclavicular hyperostosis: painful swelling of the sternum, clavicles, and upper ribs. Report of two new cases. Ann Intern Med 1977;87:192-194.

13. Roed B, Kristensen T, Thorsen S, Poulsen Block K, Afzelius P. Sternocostoclavicular hyperostosis: An ill-recognized disease. Diagnostics (Basel) 2016;6:(3). pii: E29. doi:10.3390/ diagnostics6030029.

\section{Author Affiliations}

Ralph Yachoui, MD*; Mazen Kreidy, MD†; and Brian J. Parker, MD $\neq$

*Department of Rheumatology, Marshfield Clinic, Marshfield, Wisconsin, USA; Current affiliation: Division of Rheumatology, Department of Medicine, David Geffen School of Medicine, University of California-Los Angeles, Los Angeles, California, USA

$\dagger$ Department of Pulmonary/Critical care, Marshfield Clinic, Marshfield, Wisconsin, USA

$\ddagger$ Department of Radiology, Marshfield Clinic, Marshfield, Wisconsin, USA 